\title{
PENGARUH STCW AMANDEMEN MANILA 2010 TERHADAP PROSES RECRUITMENT ABK DI PT. BSM CREW SERVICE CENTRE INDONESIA TAHUN 2016
}

\author{
Yenita Mei Anggita ${ }^{a}$, Andy Wahyu Hermanto ${ }^{\text {b }}$ dan Purwantono $^{c}$

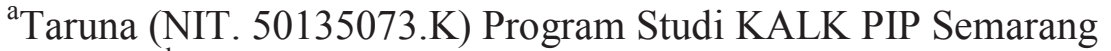 \\ ${ }^{\mathrm{b}}$ Dosen Program Studi Teknika PIP Semarang \\ ${ }^{\mathrm{c}}$ Dosen Program Studi KALK PIP Semarang
}

\begin{abstract}
STCW (Standart of Training Certification and Watch keeping for Seafarers) is a basic requirement of training, certification and watch keeping in International level that has been ratified officially, as the Manila Amendment. Based on the results of the research, from the problems mentioned are how the recruitment process, the obstacles faced from the influence of STCW Amendment Manila 2010 as well as efforts to overcome the obstacles encountered. Because it is necessary to handle so that the recruitment process in the company can run smoothly.

This research uses descriptive qualitative method that describes the existing phenomena, in detail about the recruitment process at PT. BSM Crew Service Center Indonesia and explained the obstacles and efforts undertaken to overcome these obstacles. Data are collected by observation, including description, and document analysis results.

Recruitments process conducted by the company is in accordance with established procedures. However, there are still many problems during recruitment process in PT BSM Crew Service Center Indonesia that is applicant or seafarers certificate which is not in accordance with STCW Amendment Manila 2010, the quality of applicants who do not meet the criteria of the company and applicants who have met and passed the selection stage when there is a required position was already on board on vessel. From the existing problems, efforts are made, among which the company can conduct training for seafarers who have been declared to be accepted by the company and will on-board the vessel while also giving time to ex crew seafarers who sign off from the vessel and new applicants to update the certificate and the company can expand the vacancy information to be expected that comes to apply more and more.
\end{abstract}

Keywords: recruitment, criteria, procedure

\section{PENDAHULUAN}

STCW (Standart of Training Certification and Watchkeeping for Seafarers) Manila 2010 yang mengatur tentang standar minimun yang harus dipenuhi oleh anak buah kapal berkaitan dengan pelatihan anak buah kapal atau crew, sertifikasi dan petugas jaga untuk pelaut yang sesuai dengan aturan Flag state pada saat di kapal. Seluruh pelaut harus melakukan updating sertifikat kompetensi ataupun sertifikat keterampilan harus mengikuti standar STCW Amandemen Manila 2010.

Rekrutmen adalah proses mendapatkan sejumlah calon tenaga kerja yang kualifaid untuk jabatan atau pekerjaan. Aktivitas rekrutmen dimulai pada saat calon mulai dicari dan berakhir tatkala lamaran mereka diserahkan. Melalui rekrutmen individu yang memiliki keahlian yang dibutuhkan didorong membuat lamaran untuk lowongan kerja yang tersedia di perusahaan.

Awak Kapal adalah orang yang bekerja atau dipekerjakan di atas kapal oleh pemilik atau operator kapal untuk melakukan tugas 
di atas kapal sesuai dengan jabatannya yang tercantum dalam buku sijil.

Perusahaan berupaya untuk membangun sistem SDM yang kuat secara terpadu dan bertahap baik secara kuantitas dan kualitas. Salah satu cara dalam mencari SDM yang berkualitas, yaitu melalui sistem rekrutmen.

Proses perekrutan dan seleksi crew atau anak buah kapal (ABK) PT. BSM Indonesia selama ini dilakukan menggunakan kriteria ideal. Perusahaan haruslah menjalakan pengawakan kapal yang baik untuk memenuhi armada yang ada dalam perusahaan pelayaran itu sendiri. Namun pada kenyataanya untuk pemenuhan awak kapal sering mengalami kesulitan mencari awak kapal yang sesuai kualifikasi. Sebagai contoh saat PT. BSM Indonesia membutuhkan anak buah kapal yang terdiri dari officer hingga rating untuk kapal MV. Meratus Java, mengalami kesulitan mencari $\mathrm{AB}$ (able body) dengan alasan sertifikat yang dimiliki belum memenuhi standar amandemen STCW Manila 2010, sehingga perusahaan harus mencari anak buah kapal yang benar-benar sesuai kualifikasi dan sertifikatnya telah di-update sesuai ketentuan STCW Manila 2010.

Dengan adanya tuntutan standar pelaut yang ditetapkan International Maritime Organization (IMO). Pelaut dunia termasuk dari Indonesia harus mengikuti syarat dan ketentuan Standards of Training, Certifitation and Watchkeeping (STCW) Amandemen Manila 2010. Sertifikat kompetensiataupun sertifikat keterampilan yang belum di-update mengikuti standar STCW Amandemen Manila 2010 dianggap tidak berlaku, sehingga para pelaut tidak akan bisa berlayar. Perusahaan kesulitan mencari awak kapal yang benar-benar kompeten dan sertifikatnya telah di-update.

Sehubungan dengan permasalahanpermasalahan tersebut, maka penulis memilih judul penelitian "Pengaruh STCW amandemen Manila 2010 terhadap proses recruitment ABK di PT. BSM Crew Service Centre Indonesia tahun 2016".

\section{METODOLOGI PENELITIAN}

Metode yang digunakan pada peelitian ini yaitu menggunakan metode deskriptif kualitatif, adapun tujuannya untuk mengungkapkan kejadian atau fakta, keadaan yang terjadi saat penelitian berlangsung dengan menyajikan apa yang sebenarnya terjadi. Untuk mendapatkan sumber data dalam penulisan penelitian dilakukan dengan observasi, wawancara dan studi pustaka.

Penelitian ini juga ditulis dari beberapa literatur buku, juga bersumber dari obyekobyek penelitian yang menjadi sumber data yang siap di olah dari hasil penelitian yang dilakukan oleh penulis. Penggunaan metode observasi sangat berperan dalam penulisan penelitian ini, jadi antara teori dan praktek disatukan dalam penelitian selama taruna melaksankaan praktek darat. Dalam penelitian kualitatif ini, penelitian menggunakan analisa data sebagai berikut:

1. Penyajian Data

Penyajian data adalah data informasi berdasarkan data yang dimiliki dan disusun secara baik, sehingga mudah dilihat dan dipahami tentang suatu kegiatan dan tindakan serta suatu peristiwa dalam teks naratif.

2. Pengambilan Simpulan

Berdasarkan dari data-data yang diperoleh dari berbagai sumber masih bersifat sederhana akan tetapi dengan adanya penambahan lebih lengkap akan didapatkan kesimpulan yang baik. Menarik kesimpulan merupakan cara seorang peneliti dalam menyimpulkan berbagai macam temuan data yang diperoleh selama proses penelitian berlangsung.

\section{HASIL DAN DISKUSI}

1. Bagaimana proses recruitment $\mathrm{ABK}$ di PT. BSM Crew Service Centre Indonesia?

a. Pelamar melengkapi dan menandatangani Formulir Lamaran (termasuk memberikan foto), pelamar mengajukannya ke Deputy Marine 
Manager atau Marine Officer untuk pemeriksaan dan evaluasi.

b. Deputy Marine Manager atau Marine Officer memeriksa ketepatan isi formulir lamaran dengan seksama; mengevaluasi semua dokumen asli yang diajukan, memastikan bahwa pelamar memiliki Sertifikat Kompetensi, Keahlian dan sertifikat pelatihan lainnya yang diwajibkan.

c. Sebagai bagian dari wawancara, pengalaman kerja pelamar sebagaimana dinyatakan dalam Formulir Lamarannya dicocokkan dengan Buku Pelautnya, dengan perhatian khusus kepada alasan pemberhentiannya serta kebangsaan Nahkoda dan pelaut lainnya di kapal. jika terdapat jarak waktu yang cukup lama antara masa layarnya, ditanyakan apa yang dilakukan pelamar sementara itu.

d. Pelamar segera menjalani Ishihara Blindness Test untuk memeriksa penglihatan terhadap buta warna. Pemeriksaan ini tidak berlaku bagi pelamar di bagian catering.

e. Jika pelamar tidak buta warna, maka dilakukan pemeriksaan tekanan darah (tekanan darah maksimal: 140/90), berat dan tinggi badan diukur untuk menghitung Indeks Berat Badan (BMI) (kisaran umum BMI adalah 18 sampai 33).

f. Jika semua dokumen sudah benar dan hasil pemeriksaan Ishihara Blindness dan Tekanan Darah baik, pelamar menjalani penilaian komputer. Ujian SETS dilaksanakan sesuai dengan perintah dari masing-masing Ship Manager.

g. Dimana diperlukan akan dibuat suatu daftar pelamar yang sudah menjalani ujian SETS. Nilai kelulusan dalam ujian Profesi dan Bahasa Inggris ini adalah sebagai berikut :

1) Support level $-55 \%$ pada tiap subjek;

2) Operasional level $-60 \%$ pada tiap subjek;
3) Management leve $1-65 \%$ pada tiap subjek.

h. Jika pelamar gagal mencapai nilai lulus maka pelamar diberi kesempatan kedua untuk menjalani ujian kembali. Jika pada kesempatan kedua ini pelamar tetap tidak dapat mencapai nilai lulus tersebut maka lamarannya ditolak dan segera diberitahukan atas kegagalannya memenuhi persyaratan ini.

i. Jika pelamar lulus, maka diadakan suatu wawancara mendalam dengan menggunakan formulir-formulir wawancara dan penilaian. Dalam wawancara perhatian ditekankan kepada nilai tiap subjek dalam Penilaian Komputer (SET Test), dengan pertanyaan-pertanyaan yang lebih mendalam pada nilai terendah. Pelamar diwawancara dalam Bahasa Inggris dan dievaluasi dalam hal-hal berikut :

1) Pengetahuan praktek dan teknis;

2) Penggunaan bahasa Inggris;

3) Penilaian atas Kesadaran akan keselamatan;

4) Penilaian atas sikap dan penampilan fisik; Penilaian atas pengalaman kerja dilaut (jalur, jenis kapal dan muatannya).

j. HR Marines Manager akan mengadakan wawancara kedua dan terakhir bagi perwira senior (deck dan engine). Pewawancara harus mengembangkan pertanyaan yang tidak standar. Hal ini akan memberikan penilaian yang lengkap atas pelamar. Catatan Wawancara Perwira Senior (Deck atau Engine) yang sudah lengkap disimpan sebagai bagian dari lamaran.

k. Jika lulus wawancara ini, pelamar menyerahkan semua dokumennya berikut untuk dibuat salinannya dan disertakan ke formulir lamarannya serta dipindai dan disimpan dalam database PAL (Portal Active Link) :

1) Passport;

2) Buku Pelaut; 
3) Sertifikat Kompetensi;

4) Sertifikat Keahlian;

5) Dokumen Kebangsaan Kapal (jika ada);

6) Sertifikat pelatihan lainnya (jika ada);

7) Buku Kuning.

2. Kendala-kendala yang dihadapi dari perubahan STCW Amandemen Manila 2010 terhadap proses recruitment di PT. BSM Crew Service Centre Indonesia.

Telah diketahui bahwa mulai tanggal 1 Januari 2017, sertifikat kompetensi ataupun sertifikat ketrampilan yang belum di-update mengikuti standar STCW Amandemen Manila 2010 dianggap tidak berlaku, sehingga para pelaut tersebut tidak akan bisa berlayar. Dalam penerapan ketentuan ini PT. BSM Crew Service Centre Indonesia mengalami beberapa kendala saat proses rekrutmen crew atau anak buah kapal. Adapun kendala-kendala tersebut diantaranya :

a. Secara sertifikasi crew belum memenuhi kriteria STCW Amandemen Manila 2010.

Kesadaran pelaut untuk melakukan updating sertifikat yang dimiliki masih sangat kurang, meskipun sertifikat yang mereka miliki belum expired atau habis masa berlakunya jika belum memenuhi standar STCW Amandemen Manila 2010 perusahaan tetap tidak dapat menerima pelamar baru ataupun untuk on board kapal. Pada saat pelamar mengajukan lamaran dan diperiksa sertifikat dan pengalaman berlayar sebagian besar dari mereka tidak mengetahui bahwa sertifikat yang mereka miliki belum memenuhi ketentuan STCW terbaru.

b. Secara sertifikasi crew memenuhi standar STCW Amandemen Manila 2010 tetapi tidak memenuhi kualifikasi perusahaan.
Pelamar yang sudah mengajukan lamaran dan ditolak pada tahap penyaringan awal dikarenakan tidak memenuhi standar perusahaan diantaranya tidak lulus pemeriksaan uji Ishihara atau buta warna, tidak lulus penilaian komputer, gagal dalam wawancara dan faktor lain, ditolak oleh HR Marine Department dan alasan-alasan lain sebagaimana diberikan. Agar pelamar dapat memenuhi kriteria atau kualifikasi perusahaan maka kandidat baru yang berumur di atas 60 tahun tidak akan diterima. Pelamar tidak buta warna, dilakukan pemeriksaan tekanan darah (tekanan darah maksimal: 140/90), berat dan tinggi badan diukur untuk menghitung Indeks Berat Badan (BMI) kisaran umum BMI adalah 18 sampai 33. Untuk pelamar yang melakukan tes maritime English harus mendapatkan score $50 \%$ untuk ratings, $55 \%$ untuk Junior Officer dan Cadets, $60 \%$ untuk Senior Officer. Pelamar yang tidak mampu mencapai score tersebut berkesempatan untuk mengulang satu kali.

c. Crew secara sertifikasi dan kualifikasi memenuhi tetapi sudah on-board.

Pelamar yang telah melalui tahap rekrutmen dan dinyatakan lulus, dan dianggap mungkin berguna bagi perusahaan nantinya. Formulir pelamar disimpan dan dimasukkan ke dalam database pelamar diterima. Marine Officer memeriksa daftar kebutuhan anak buah kapal apabila belum ada posisi maka formulir data pelamar disimpan. Dan selanjutnya jika telah dibutuhkan anak buah kapal yang cocok dalam database pelamar diterima dan setelah dihubungi dan diminta melapor ke kantor ternyata crew sudah on-board kapal ataupun bergabung dengan perusahaan lain.

\section{Upaya-upaya yang dilakukan untuk mengatasi kendala-kendala yang dihadapi perusahaan.}


Terkait kendala-kendala yang dihadapi, adapun beberapa upaya yang dapat dilakukan diantaranya

a. Meningkatkan mutu Sumber Daya Manusia. Untuk memenuhi kriteria perusahaan dalam proses rekrutmen, perusahaan dapat melakukan in-house training dan familiarisasi di kantor PT. BSM Crew Service Centre Indonesia kepada anak buah kapal yang telah dinyatakan diterima oleh perusahaan dan akan on-board kapal. Dengan melakukan in-house training diharapkan agar pelaut atau anak buah kapal Indonesia lebih siap untuk bersaing dengan pelaut dari negaranegara lain. Beberapa in-house training yang terdapat di PT. BSM Crew Service Centre Indonesia diantaranya :

1) MRM - Maritime Resources Management Course (5-Days)

2) RAAA - Risk Assessment \& Accident Analysis (2-Days)

3) SSO - Shipboard Safety Officer Course (5-Days)

4) PMS - Planned Maintenance System Course (5-Days)

5) AIS - Automation Identification System Course (1-Day)

6) ISM/ISPS - Introduction to ISM \& ISPS Code (1-Day)

7) $\mathrm{MEC}$ - Maritime English Course

8) MS Office - Microsoft Office Aplication Course

b. Memberikan waktu kepada anak buah kapal atau ex crew yang telah turun kapal untuk melakukan update sertifikatnya yang belum mengalami perubahan Amandemen STCW Manila 2010. HR. Marine Officer melakukan pengecekan sertifikat dan dokumen-dokumen para anak buah kapal yang perlu dilakukan revalidasi sertifikat, perpanjangan seperti seaman book, passport yang masa berlakunya telah habis maupun updating untuk sertifikat yang belum diperbaharui sesuai Amandemen Manila 2010.

c. Iklan lowongan dalam media lokal. Berdasarkan daftar kebutuhan segera ABK dalam jaringan komputer dan mendesaknya kebutuhan tersebut maka Deputy Marine Manager akan mendiskusikan dengan Marine Officer mengenai pencarian dari sumbersumber berikut :

1) Mess atau asrama pelaut;

2) Pusat Pelatihan Maritim;

3) Tempat berkumpul Pelaut; dan

4) Korespondensi pelamar.

Calon pelamar diberitahukan untuk :

1) Melapor ke kantor BSM untuk pemeriksaan dan wawancara dengan membawa dokumen asli; atau

2) Mengajukan lamaran secara elektronik.

Dengan demikian akan membantu memudahkan peusahaan dalam mencari pelaut dan anak buah kapal. Diharapkan setelah dilakukan melalui sumber-sumber di atas akan lebih banyak pelamar yang datang ataupun mengirimkan lamaran melalui elektronik sehingga perusahaan memiliki banyak kandidat untuk diseleksi dan evaluasi sesuai standar perusahaan.

\section{KESIMPULAN}

Berdasarkan uraian-uraian pada bab sebelumnya, tentang Pengaruh STCW Amandemen Manila 2010 terhadap Proses Recruitment di PT. BSM Crew Service Centre Indonesia tahun 2016, maka sebagai bagian akhir dari penelitian ini penulis memberikan kesimpulan dan saran yang berkaitan dengan masalah yang dibahas dalam penelitian ini, yaitu :

1. Proses recruitment yang ada di PT. BSM Crew Service Centre Indonesia sudah dilakukan sesuai dengan prosedur yang 
telah ditentukan. Setelah pelamar datang mengisi formulir lamaran ke perusahaan kemudian akan diperiksa oleh staf untuk dilihat keaslian sertifikat dan dokumen serta pengalaman berlayar selanjutnya diproses oleh Marine Officer. Selanjutnya dalam proses pemeriksaan dan evaluasi adalah Marine Officer atau Deputy Marine Manager dengan metode seleksi yang digunakan yakni wawancara berdasarkan curriculum vitae yang lolos dari tes penyaringan awal. Proses seleksi wawancara calon ABK, apabila dinilai bagus dari hasil wawancara selanjutnya dilakukan tes Bahasa Inggris dan harus mendapatkan nilai yang sudah menjadi standar perusahaan.

2. Kendala-kendala yang ditemui penulis dan sering terjadi pada saat proses recruitment di PT. BSM Crew Service Centre Indonesia adalah sertifikat pelamar atau pelaut yang belum sesuai dengan ketentuan STCW Amandemen Manila 2010, kualitas pelamar yang tidak memenuhi kriteria perusahaan dan pelamar yang telah memenuhi dan lulus tahap seleksi ketika ada posisi yang dibutuhkan ternyata sudah on board kapal

3. Berdasarkan kendala-kendala yang dihadapi dapat dilakukan beberapa upaya yang diantaranya perusahaan dapat melakukan training untuk para pelaut yang telah dinyatakan diterima oleh perusahaan dan akan on-board kapal selain itu juga memberi waktu kepada pelaut ex crew yang turun kapal maupun pelamar baru untuk melakukan updating sertifikat yang dimiliki, dan perusahaan dapat memperluas informasi lowongan agar diharapkan yang datang mengajukan lamaran semakin banyak.

\section{DAFTAR PUSTAKA}

International Maritime Organization, Standart Of Training, Certification and Watchkeeping for Seaferers 1987/95 Convention and Code,
Including Manila Amandement 2010, London

Kosasih, Engkos dan Soewedo, Hananto. 2012. Manajemen Perusahaan Pelayaran. Jakarta : PT. Rajagrafindo Persada

Menteri Perhubungan Republik Indonesia Nomor PM 84 Tahun 2013 Tentang Perekrutan dan Penempatan Awak Kapal

Peraturan Menteri Perhubungan Republik Indonesia Nomor PM 70 Tahun 2013 Tentang Pendidikan dan Pelatihann, Sertifikasi serta Dinas Jaga Pelaut.

Rivai, V \& Sagala, E. 2013. Manajemen Sumber Daya Manusia untuk Perusahaan. Jakarta : Rajawali Pers

Sedarmayanti. 2011. Sumber Daya Manusia dan Produktivitas Kerja. Bandung : CV. Mandar Maju

Sugiyono. 2013, Metode Penelitian kuantitatif, kualitatif dan $R \& D$. Bandung : Alfabeta

Undang-Undang RI No.17 Tahun 2008 tentang Pelayaran

Wahjono, Sentot Imam. 2015. Manajemen Sumber Daya Manusia. Jakarta : Salemba Empat

www.dephub.go.id

www.bsm-indonesia.com 